\title{
Knowledge Sharing and Creating Process in a Social Development Project: Developing a Model for Intra-Project Knowledge Management
}

\author{
Masahiro Oseko \\ Nevka Co., Ltd., Tokyo, Japan \\ Email: masahiro.oseko@nifty.com
}

How to cite this paper: Oseko, M. (2017) Knowledge Sharing and Creating Process in a Social Development Project: Developing a Model for Intra-Project Knowledge Management. Open Journal of Social Sciences, 5, 117-127.

https://doi.org/10.4236/jss.2017.510011

Received: September 20, 2017

Accepted: October 10, 2017

Published: October 13, 2017

\begin{abstract}
This research investigated the sharing, experimenting and creating process of knowledge in a social development project implemented by Dhaka city, Bangladesh with the assistance of Japanese government. Most of the international cooperation organizations such as the World Bank are interested in inter-project knowledge management but less in intra-project knowledge management. These organizations mainly focus on storing and sharing of knowledge centering on their headquarters, but not reach out to each one of their projects. However, knowledge is presented, shared, experimented, and created in the field of each project. Conducting a fieldwork and using qualitative research methods, the author closely observed the knowledge process of the project and found that the knowledge was created through the interaction of optimizing and satisfying, rationalistic plan and incremental plan, universal knowledge and local knowledge, and learning and reflecting. Based on these findings, this paper presents a model of knowledge management in a social development assistance project, which was named "PAR model", a spiral process model of three phases of Planning, Acting, and Reflecting.
\end{abstract}

\section{Keywords}

Local Knowledge, Universal Knowledge, Bounded-Rational Plan, Muddling Through

\section{Introduction}

This case study research examines the knowledge process of a social development assistance project. 
A project, by definition, is a temporary endeavor implemented by a temporary team. Therefore, knowledge created in a project can be dispersed together with the dissolution of the team unless otherwise it is properly managed [1]. This is also true in project-based organizations such as the World Bank and JICA (Japan International Cooperation Agency) involved in development assistance. Knowledge management activities of these organizations, however, mainly focus on storing and sharing of knowledge in their organizations and networks, but not reach out to each one of their projects [2]. This is also true in the academic research. Although there is extensive literature covering inter-projects knowledge management, a focus on intra-project knowledge management in a project appears to be very limited [3]. With this background, this paper presents a theoretical model and practical implications for knowledge management in social development assistance projects.

The research question is "how knowledge has been shared, experimented and created in Clean Dhaka Project?" Clean Dhaka Project (2007-2013) was the case of this study, which was an international cooperation project on solid waste management implemented by the collaboration of Dhaka city, Bangladesh and JICA. The author conducted one-month participatory observation of the project in 2013. Data were collected through document review, participatory observation, and interviews with stakeholders including project team members, local government officials, private sectors, and local residents. Qualitative data analysis was applied on these survey results using data analysis method of SCAT (Steps for Coding and Theorization) [4].

\section{Case Study}

Solid waste management (SWM) is a set of activities that includes the collection, transportation, processing, and disposal of waste. The collection is a process of carrying waste from households, shops or business premises to street collection spots predetermined generally by a local government. The transportation includes the loading, unloading and transfer of waste to a treatment plant or disposal site. In the processing, waste is pretreated to be composted or incinerated before the final disposal. The waste and incinerated ash is transported to a final disposal site to be landfilled. The sweeping of streets and public spaces, the cleaning of open drains and the removal of these wastes are also included in SWM [5].

In urban areas of many developing countries, the highest priority is placed on the collection and transportation. The reason for this is because politicians, administrators and residents do not want to see waste in their towns [6]. Accordingly, the biggest part of the SWM budget is spent on collection and transportation [6] [7]. Collection and transportation account for more than $50 \%$ of the SWM budget in some developing countries' capital cities such as Rio de Janeiro [8].

Compared with other SWM components, it is not easy to improve collection and transportation because they are conducted in unique localities with indivi- 
dualized soft and hard socio-economic infrastructure. In order to operate in local environments, collection and transportation of waste must be designed and implemented specifically for the unique situation of each area considering households, communities, roads, streets, etc. Because of this, a versatile model for collection and transportation of urban SWM is hard to create.

This also applies to international cooperation projects. Introduction of crushing and compression facilities, incineration plants, and composting systems for processing and hygienic landfill for disposal are typical approaches applied by the World Bank, ADB (Asian Development Bank) and JICA. However, for collection and transportation, reviewing and finding a locally appropriate collection and transportation system itself is targeted as one of the main purposes in many SWM projects [7].

Given this situation, an international cooperation project, the Project for Strengthening of Solid Waste Management in Dhaka City, Bangladesh (2007-2013), so called the Clean Dhaka Project (hereinafter referred to as "the project"), has developed a collection and transportation system called a ward-based approach (WBA), which made a notable contribution to the improvement of SWM of Dhaka city [9].

The project was planned by three surveys, namely, a short-term expert survey (2000), a development survey (2003-2006) and a preliminary survey (2006). The first two surveys were conducted by Japanese consultants hired by JICA, while the last survey was conducted mainly by JICA officials. The short-term survey was conducted for 6 months by a Japanese consultant with the assistance of two engineers of DCC. The purpose of the survey was to study the situation of SWM of DCC including legal structure, administrative system, financial situation, behavior of citizens, and to make suggestions for the improvement of SWM of DCC [10]. After three-year interval, the development survey was conducted from 2003 to 2006 for 26 months by a consultant team consisted of 14 Japanese consultants with the assistance of engineers and street level bureaucrats called conservancy inspectors (CIs) of DCC. The survey produced a master plan of the city for the comprehensive improvement of SWM setting the target on 2015 or 10 years after. The survey also implemented some small-scale pilot projects to find the feasibility of the master plan [11]. Six months after the development survey, in 2006, the preliminary survey was conducted for 10 days by a five Japanese survey team for formulating a plan of the Clean Dhaka Project.

The four-year Clean Dhaka Project commenced in February 2007 aiming at the increase of collection volume of waste from 1,400 ton/day in 2007 to 2,053 ton/day in 2011. The target was intended to be achieved through the five components of 1) improvement of the DCC's management and coordination capacity, 2) promotion of local residents' participation, 3) improvement of collection and transportation, 4) improvement of final disposal sites, and 5) improvement of accounting system of SWM of DCC. The project team was formulated in DCC, and a team of 10 Japanese consultants was sent as an advisor team. 
About one year after the commencement, the project stagnated with three challenging situations. The first trouble was the resistance of waste collection truck drivers. While the project tried to change the collection routes of trucks to be more rational and efficient, the truck drivers strongly resisted by boycotting the project activities. That was because the drivers demanded and accepted commissions from shops, residents and even from waste pickers on their collection routes.

The second trouble was that the establishment of the integrated SWM department in DCC was hardly realized. The SWM was carried out by three different departments in DCC before the project, and due to the lack of collaboration and coordination of these departments, SWM by the city was poorly carried out. Therefore, the project planned to establish the Waste Management Department (WMD) by integrating these three departments. However, due to the rigid and inefficient organizational structure, complicated decision-making mechanisms and conflicts of interests and power in the city [12], while the WMD was established on paper, most of its posts were vacant or temporary assignments.

The third trouble was caused by the project plan. Even though they implemented project activities as planned, the SWM of the city as a whole did not seem to be improved. The reason for this was because the activities of the project had been disjointed but not linked with each other. Activities for the promotion of community participation completed as they were, and not being linked with other components such as collection and transportation, and vice versa.

Because of these troubles, the project deadlocked for some months, and Japanese and Bangladeshi project team members were highly frustrated. In these situations, one of the Japanese team members, who had over 20 years of experience in SWM in Tokyo Metropolitan Government, conceived of an idea of integration of collection, transportation, cleaning and local participation. This integration system was named as ward-based approach (WBA). WBA consisted of four components, i.e., 1) construction of an office in each ward as a front-line base of SWM of the city, 2) improvement of working conditions of clearers, 3) improvement of collection through the promotion of community participation, and 4) improvement of transportation through the introduction of new collection vehicles such as compactors. In WBA, these four components were closely linked and expected to work as a small but a wholistic total system in each ward.

Even in a ward, major occupations of residents, housing types, community organizations and infrastructures are different from area to area. Therefore, in order to materialize the concept of WBA, its ways of operation and coordination of four components had to be customized fitting to their localities. This customization was done by local residents with the facilitation of CIs who had direct and close contact with communities and knew well the local situations.

WBA functioned as expected integrating the SWM system in Dhaka city. The project muddled through the situation by virtue of WBA. But in the third year of the project, just in the middle of the project period, another difficulty had come. It was obvious that the number of DCC's waste collection trucks was far less 
than enough, and most of them were old and disabled. JICA, therefore, sought a means and managed to procure 100 new collection vehicles from some other program other than the project. It was unexpected good news for the project. But at the same time, it meant that the project was burdened with the unexpected task of operationalization of 100 new vehicles including compactors DCC had no experience to operate. Since the resistance of truck drivers backed up by the driver's union had not ceased, the new vehicles did not move at all almost a year.

About a year after the delivery of new vehicles to the project, an official of DCC introduced one of his relatives to the project as a driver of the vehicle. One of the 100 new vehicles thus started moving in Dhaka city in June 2010. Some weeks after that, another official introduced some of his relatives and friends as drivers, and some vehicles started moving. Seeing the slow but steady operationalization of new vehicles, the DCC decided to advertise driver's jobs in newspapers. Along with the changes of the situation, the driver's union and its members had softened their attitudes toward the project. By the end of the extension phase of the project in February 2013, all of 100 waste collection vehicles were fully operationalized.

The progress of the project was periodically reviewed and evaluated. Semi-annual and annual progress reports were produced by the project team. Japanese and Bangladeshi team members in collaboration looked back their activities, analyzed successful/ unsuccessful factors, drawn lessons learned, and fed back them to their next period's action plans. Evaluations were conducted in the middle and at the end of the project by the third parties with the support of JICA. The evaluation teams reviewed the achievements of outputs and the purpose of the project, analyzed successful/ unsuccessful factors, made recommendations for the project, and drawn lessons learned for other projects in future. The terminal evaluation in August 2010 found that WBA was successful but not fully extended in the city, and only some of 100 new collection vehicles were in operation. The evaluation team, therefore, recommended extending the project for another two years. The project was extended accordingly. The terminal evaluation for the extension phase was conducted in November 2012, and found that WBA was realized in 33 wards out of the total of 90 wards, and all of 100 new vehicles were fully operationalized. The evaluation team highly evaluated the contribution of the project to the improvement of SWM of DCC, and recommended to terminate the project as planned. The six-year technical cooperation project thus came to an end in March 2013.

\section{Discussion}

\subsection{Project Planning}

Since accountability is highly required in public domain, ODA (official development assistance) projects are planned in rationalistic way. A rationalistic plan is formulated by analysis, modelling and calculation, and aims at the optimum 
results. However, human rationality is limited by the risk and uncertainty, incomplete information, complexity, and environmental constraints [13]. Besides, the problems presented to problem solvers by the world are ill-structured problems [14]. Therefore, a rationalistic plan is inevitably bounded, and settles for a satisfactory, rather than an optimization [13]. In this paper, this kind of rationalistic plan is named as a "bounded-rational plan". Because the plan made for the Clean Dhaka Project was a bounded-rational plan, the execution process of the project became a muddling-through process [15].

Insufficient sharing of context-specific knowledge or local knowledge [16] [17] had become another cause of muddling proceedings of the project. Since it was the first time for DCC to work with JICA, they did not exactly know what JICA would do in the project. Therefore, DCC staff did not know what information and knowledge they should share with JICA. Information about the bribery of truck drivers and difficulties of organizational restructuring was provided from DCC to JICA, but it was not easy to share the historical, cultural and social context of these issues. Japanese side, therefore, knew these issues but did not well understand their seriousness and difficulties, and thought they could solve these problems by implementing the project.

With this background, the project plan was formulated mainly by the Japanese side with typical components of SWM projects such as the establishment of central SWM department, promotion of community participation, and introduction of sanitary landfill. In other words, the plan was made of universal knowledge which had been typically and popularly applied to SWM projects all over the world. Universal knowledge is de-contextualized, abstract knowledge free from any localities. Therefore, they are disjointed each other. When they are applied to any specific situation, they have to be coupled and organized as a total system fitting to the locality. Otherwise, the plan would be a bunch of disjointed components.

\subsection{Project Execution}

No matter how well prepares, a plan is bounded-rational. And there is no crystal ball which tells us the future. Therefore, most of the project executions are disrupted by unforeseeable events. That was also the case of Clean Dhaka Project. Besides, because the plan was made of disjointed components, implementation of project activities did not produce a systemic improvement of SWM of the city. However, the project overcame these situations by introducing WBA and the help of DCC's individuals' kinships and territorial connections.

WBA was conceptualized by Japanese who had a long experience of SWM in Tokyo. The idea of WBA rooted in the local knowledge fostered in Tokyo. And in Dhaka city, WBA was materialized through customization by local knowledge of CIs and local residents. WBA was thus created by the integration of local knowledge of Japanese and Bangladeshi. Besides, since WBA was a system integrating collection, transportation, cleaning and community participation, in the way of realizing this system, disjointed components of the project were gradually 
integrated. Also, the problem of the operation of 100 new trucks was solved by local knowledge of Bangladeshi, which mobilized their network of kinships and territorial connections.

In the initial planning stage, local knowledge of Japanese and Bangladeshi was not sufficiently presented and shared. But in the project execution stage, they shared the situations or "Ba (field)" in which individuals shared experiences and synchronized their bodily and mental rhythms [18], and in "Ba" they shared their local knowledge.

\subsection{Project Evaluation}

There were two types of evaluation in Clean Dhaka Project. One was a progress review done by the project team members. While the purpose of this review was to report the progress to JICA and DCC, the substantial value of this review for the project was to analyze successful/unsuccessful factors, draw lessons learned, and feedback them to the next period's action plans. This review was, therefore, a process of extracting and utilizing lessons learned by learners themselves.

Another type of evaluation was a formal evaluation by the third party. The Japan's Ministry of Foreign Affairs defines the purpose of the ODA's evaluation as accountability and learning [19]. The evaluation for accountability is so called the evaluation for compliance [20]. The evaluation for learning by the third party is conducted through document study and interviews with project team members. The learning of the project is thus evaluated through indirect way, and the evaluation of learning by learners themselves is not included in the evaluation.

\subsection{Project Cycles}

Seeing the progress of the project through time, a spiral process consists of three phases of Plan-Do-See can be observed. One cycle of Plan-Do-See corresponds to the Japan's fiscal year (JFY), since it was required for the project to submit an annual progress report to JICA and DCC at the end of the JFY. A progress review or an evaluation was carried out at least once a year, and the results of them were fed back to the plan of the next phase. Therefore, the project plan or action plans were updated every year (See Figure 1).

\section{Conclusion}

\subsection{Answers to the Research Question}

Five major findings were made as the answers to the research question. First, the knowledge process of the project proceeded along with the orthodox Plan-Do-See cycle. Second, the first project plan was created mainly by the Japanese side with conventional means typically applied in developing countries. Third, although the project was stagnated by the problem unique to the context of Dhaka city, the situation was overcome with some ideas originated in Japan but was customized to fit to the locality. Fourth, the project activities and their results were 


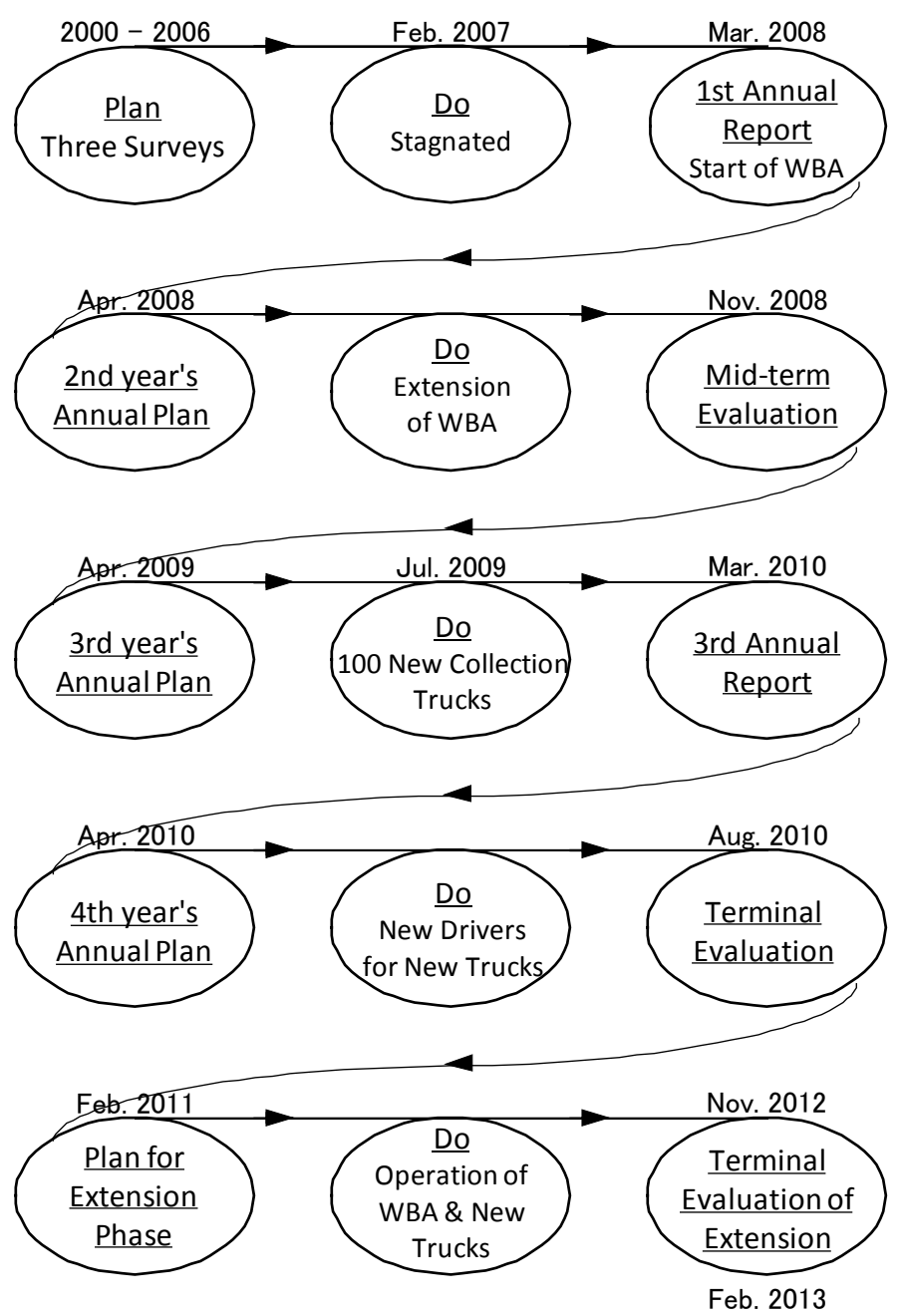

Figure 1. Five cycles of clean dhaka project.

periodically reviewed, analyzed, and documented. Fifth, the project plan was updated incorporating the knowledge acquired in the previous phases.

\subsection{Theoretical Implications}

As a theoretical implication, the author proposes a model of knowledge management in a social development assistance project. The model is named "PAR model", a spiral process consists of three phases of Planning, Acting, and Reflecting (See Figure 2).

In the Planning phase, knowledge of "understanding of current situation" is shared by the both sides of donor and recipient. In the understanding of current situation, "understanding of problems" is included. Based on the shared understanding of current situation and universal and local knowledge, knowledge of "solutions for problems" is created. Solutions for problems are structured in a "project plan" as an explicit knowledge. The project plan illustrates a "future vision". Therefore, knowledge created in the Planning phase is understanding of current situation including problems, solutions for problems, a project plan, and 


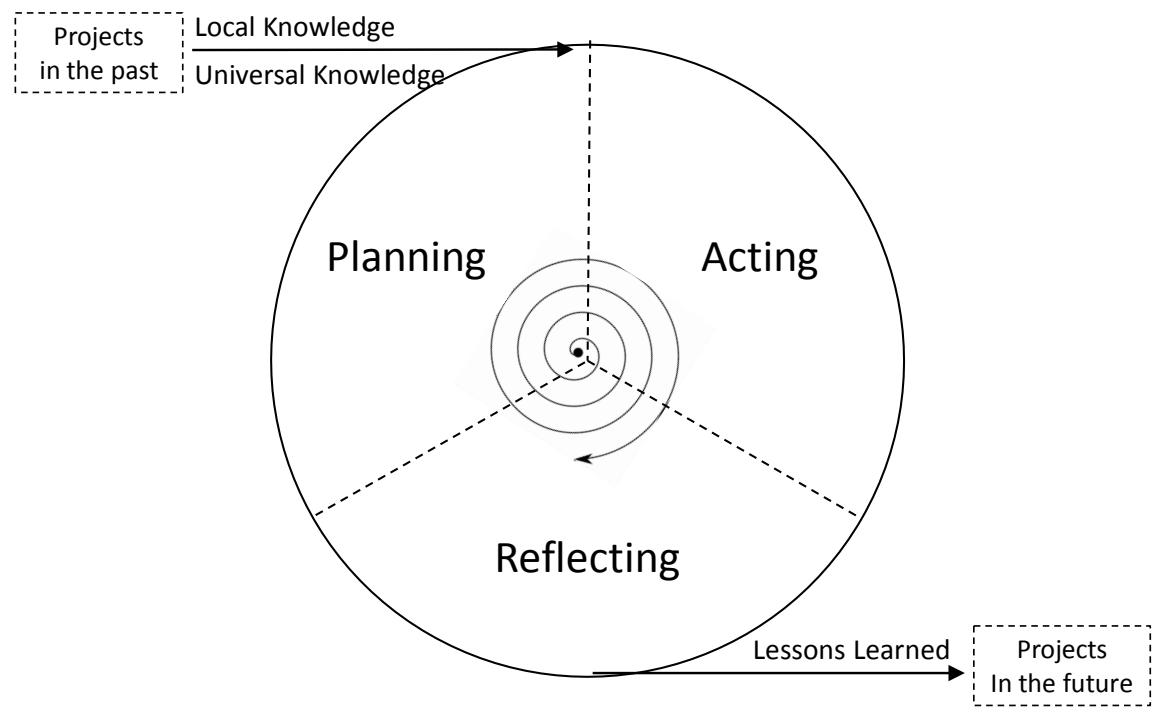

Figure 2. PAR Model for knowledge management of social developoment assistance project.

a future vision. The plan produced in the very first planning phase tends to be a decontextualized plan with insufficient local knowledge.

The next phase is named Acting instead of Doing, because a term of Doing is vague and too broad. Acting, on the other hand, carries a connotation of specific and flexible action adaptive to the situation. In the Acting phase, the project starts activities as planned, but facing context specific problems, the project starts muddling. In the struggling process for seeking the solutions of the problems, both sides of donor and recipient share their understanding of current situation and local knowledge. Applying shared knowledge, the project conducts iterative experiments to find better solutions. In this process, the project produces "practical knowledge". Since the situation is changed due to the experiments, understanding of current situation must be updated. Therefore, knowledge created in the Acting phase is practical knowledge and updated understanding of current situation.

The following phase is named Reflecting instead of Seeing, because Seeing is also too vague and broad. And the term of "reflection" is used as a learning and feedback process including evaluation as one of its components [21] [22]. In the Reflecting phase, the project looks back its learning, integrates the knowledge created, extracts lessons learned for the next phase or for the projects in future, and compiles them in a report. The report is shared with stakeholders, and stored in the project implementing organizations as their intellectual assets. Therefore, knowledge created in the Reflecting phase is integrated knowledge and lessons learned.

In the Planning phase of the second cycle, the project plan is updated to be a more context-adaptive one. Thus, the model illustrates the evolution process of knowledge from the rationalistic but distant one to the incremental but context-adaptive one via the muddling through process. 


\subsection{Practical Implications}

As for practical implications, this study emphasizes the importance of the optimum understanding of the current situations rather than making a highly sophisticated plan, because a plan is a prediction or a bounded-rational plan at best. The wide and deep understanding of the current situations makes the project to be flexible and adaptable to the local context.

\subsection{Suggestions for Future Research}

For future research, the author suggests more case studies to examine the validity of the PAR model in other fields, regions, and donor organizations.

\section{References}

[1] Prencipe, A. and Tell, F. (2011) Inter-Project Learning: Process and Outcomes of Knowledge Codification in Project-Based Firms. Research Policy, 30, 1373-1394. https://doi.org/10.1016/S0048-7333(01)00157-3

[2] World Bank (2016) Solid Waste Management Strategic Planning. http://web.worldbank.org/WBSITE/EXTERNAL/TOPICS/EXTURBANDEVELOP MENT/EXTUSWM/0, contentMDK:20239682 menuPK:497744 pagePK:148956 p iPK:216618 theSitePK:463841,00.html

[3] Knowledge Management for Development (2017) KM4D Journal, List of issues. http://wiki.km4dev.org/List of issues

[4] Otani, T. (2008) SCAT a Qualitative Data Analysis Method by Four-Step Coding: Easy Startable and Small Scale Data-Applicable Process of Theorization (in Japanese with English Abstract. Educational Sciences, 54, 27-44.

[5] United Nations Human Settlements Programme (UN-HABITAT) (2010) Collection of Municipal Solid Waste in Developing Countries. UN-HABITAT, Nairobi.

[6] Overseas Environmental Cooperation Center (OECC) (2004) International Cooperation in the Field of Solid Waste Management. OECC, Tokyo.

[7] Japan International Cooperation Agency (JICA) (2009) Thematic Guidelines on Solid Waste Management. JICA, Tokyo.

[8] Sakurai, K. (2000) Urban Solid Waste Management in Developing Countries (in Japanese). Waste Management Research, 11, 142-151.

https://doi.org/10.3985/wmr.11.142

[9] JICA (2013) Final Evaluation Report of the Project for Strengthening of Solid Waste Management in Dhaka City (Extension Phase), Bangladesh. JICA, Tokyo.

[10] JICA (2000) Solid Waste Management Project of Dhaka City Corporation: Final Report. JICA, Tokyo.

[11] JICA (2005) The Study on the Solid Waste Management in Dhaka City, Final Report Vol. 2, Main Report. JICA, Tokyo.

[12] JICA (2010) Final Evaluation Report of the Project for Strengthening of Solid Waste Management in Dhaka City, Bangladesh. JICA, Tokyo.

[13] Simon, H. (1972) Theories of Bounded Rationality. In: McGuire, C.B. and Radner, R., Eds., Decision and Organization. Elsevier, Amsterdam, 161-176.

[14] Simon, H.A. (1973) The Structure of Ill Structured Problem. Artificial Intelligence, No. 4, 181-201. https://doi.org/10.1016/0004-3702(73)90011-8

[15] Lindblom, C. (1959) The Science of "Muddling Through". Public Administration 
Review, 19, 79-88. https://doi.org/10.2307/973677

[16] Geertz, C. (1983) Local Knowledge. Basic Books Inc., USA.

[17] Nolan, R. (2002) Development Anthropology. Westview Press, Cambridge.

[18] Nonaka, I. and Takeuchi, H. (1995) The Knowledge-Creating Company: How Japanese Companies Create the Dynamics of Innovation. Oxford University Press, New York.

[19] Ministry of Foreign Affairs of Japan (MOFA) (2016) ODA Evaluation Guidelines 10the Edition. MOFA, Tokyo.

[20] Mondal, A. and Dutta, S. (2007) Monitoring for Outcome in Community Driven Projects, Using a Learning Based Approach. Academic Foundation, New Delhi. The World Bank, Washington DC.

[21] Reid, B. (1993) But We're Doing It Already! Exploring a Response to the Concept of Reflective Practice in Order to Improve Its Facilitation. Nurse Education Today, 13, 305-309. https://doi.org/10.1016/0260-6917(93)90058-A

[22] CARE International (2014) RMERL: Participatory Monitoring, Evaluation, Reflection and Learning for Community-Based Adaptation: A Revised Manual for Local Practitioners. CARE International, London. 